\title{
Defect-assisted tuning of electroluminescence from p-GaN/n-ZnO nanorod heterojunction
}

\author{
LAWRENCE S VIKAS ${ }^{1}$, C K SRUTHI ${ }^{1}$ and MADAMBI K JAYARAJ ${ }^{1,2, *}$ \\ ${ }^{1}$ Nanophotonic and Optoelectronic Devices Laboratory, Department of Physics, Cochin University of Science \\ and Technology, Kochi 682 022, Kerala, India \\ ${ }^{2}$ Center for Advanced Materials, Cochin University of Science and Technology, Kochi 682 022, Kerala, India
}

MS received 18 November 2014; accepted 16 January 2015

\begin{abstract}
Growth of nanostructured $\mathrm{ZnO}$ by solution process always lead to the formation of various kinds of defects. Defect states also can aid in improving different properties of the material. In the case of light-emitting diodes (LEDs), major research is focused on tuning the emission colour so as to achieve white emission without the use of any phosphors. Vertically aligned $\mathrm{ZnO}$ nanorods were grown over Mg:GaN substrate by hydrothermal process. High-resolution X-ray diffraction (HRXRD) analysis confirms the epitaxial growth of nanorods over the substrate. The photoluminescence (PL) studies revealed a narrow near band edge emission and a broad defect-induced deep level emission. The intensity of deep level emissions related to $\mathrm{Zn}_{\mathrm{i}}, \mathrm{V}_{\mathrm{o}}, \mathrm{O}_{\mathrm{i}}$ defects decreases on annealing. The $V-I$ characteristics of the heterojunction showed excellent rectifying nature with electroluminescence emission on forward bias. Device fabricated by as-grown $\mathrm{ZnO}$ nanorods emits in the UV-blue region and broad emission in the visible region. While the annealed device emitted only in UV-blue region. The emission wavelengths closely matched with that of defect state emissions obtained in the PL studies. By annealing, various defect states density can be controlled, thereby emission colour tuned from white to blue.
\end{abstract}

Keywords. Heterojunction; ZnO; GaN; LED; hydrothermal.

\section{Introduction}

Light-emitting diodes (LEDs) are nowadays replacing conventional illumination light sources. Its range of emission colours, high output power, low cost, low power consumption are the features that favour the application of LED in solid state lighting. In most LEDs white light emission has been realized with the help of phosphor materials. Scientists are searching for alternatives to produce phosphor-free LEDs. Avoiding the inefficient phosphor will improve the quantum efficiency. LEDs with various colours are always fancy; possibility of tuning the emission colour is even more appealing. One of the most promising wide band gap $\left(E_{\mathrm{g}}=3.39 \mathrm{eV}\right)$ semiconductor for LEDs is GaN. In recent times $\mathrm{GaN}$ based LEDs gains much interest due to its potential applications. The 2014 Nobel prize is awarded to Isamu Akasaki, Hiroshi Amano and Shuji Nakamura for their efforts in realizing GaN-based LEDs. They developed a successful technique for the growth of good quality p-type thin films using modified MOCVD process. ${ }^{1,2}$ There are many reports on LEDs based on GaN which emits $\mathrm{UV}^{3}{ }^{3}$ and other colours with the help of phosphors. ${ }^{4-6} \mathrm{ZnO}$ is a wide band gap material $\left(E_{\mathrm{g}}=3.37 \mathrm{eV}\right)$ with exciton binding energy of

\footnotetext{
*Author for correspondence (mkj@cusat.ac.in)
}

$60 \mathrm{meV}$. Nanostructured $\mathrm{ZnO}$ can be grown by various techniques including solution processes. Hydrothermal synthesis is one such technique to form various nanostructures. By choosing right precursors and experimental condition one can produce variety of nanostructures including nanoparticles, nanoflowers, nanorods, nanoribbons, etc. $\mathrm{ZnO}$ is intrinsically n-type semiconductor. Growth of semiconductors in nanorod form will reduce the grain boundaries allowing barrier free carrier transport. Lower number of grain boundaries reduces the non-radiative recombination losses, increasing the output power of LEDs. Thus, combining $\mathrm{n}-\mathrm{ZnO}$ with $\mathrm{p}-\mathrm{GaN}$ can form good heterojunction with excellent light emission properties. $\mathrm{GaN}$ or $\mathrm{Mg}: \mathrm{GaN}$ layer is formed by the metal organic chemical vapour deposition (MOCVD) technique. The $\mathrm{ZnO}$ layer and their heterojunctions are grown by various techniques like MOCVD ${ }^{7}$ plasma-assisted MBE (PAMBE) ${ }^{8}$ dip-coating, ${ }^{9}$ hydrothermal synthesis, ${ }^{10,11}$ electrodeposition, ${ }^{5}$ etc. $\mathrm{ZnO}$ layer in $\mathrm{n}-\mathrm{ZnO} / \mathrm{p}-\mathrm{GaN}$ heterojunction is grown in the form of $1 \mathrm{D}$ nanostructures including nanorods, ${ }^{5,7,8,10-12}$ nanocones ${ }^{13}$ or nanotubes. ${ }^{9}$ Among them major interest is on the growth of $\mathrm{ZnO}$ nanorods especially solution processed $\mathrm{ZnO}$ nanorods. Solution grown nanorods are always prone to defect formation. These defect states can be controlled by experimental conditions. In this work we demonstrate the dependence of defect states on conduction mechanism of hydrothermally synthesized $\mathrm{ZnO}$ nanorods. Tuning the defect states of $\mathrm{ZnO}$ nanorods showed remarkable 
change in the emission properties. The emission threshold of present LEDs are lower than previous reports on similar structure. $^{10,14}$

\section{Experimental}

p-type Mg:GaN substrate purchased from MTI corporation has a structure $350 \mu \mathrm{m}$ sapphire/1.5 $\mu \mathrm{m}$ GaN/2 $\mu \mathrm{m}$ $\mathrm{GaN}: \mathrm{Mg}$. Prior to the growth of $\mathrm{ZnO}$ nanorods, the $\mathrm{Mg}: \mathrm{GaN}$ substrates were cleaned in ultrasonic bath of acetone, isopropyl alcohol and water. Vertically aligned $\mathrm{ZnO}$ nanorods were grown on C-cut $\mathrm{Mg}: \mathrm{GaN}$ substrate by hydrothermal process. Aqueous solution of zinc acetate and $\mathrm{NH}_{4} \mathrm{OH}$ were used as precursor solution for hydrothermal synthesis. The substrate along with the precursor solution was placed inside an autoclave kept at $180^{\circ} \mathrm{C}$ for $1 \mathrm{~h}$. After hydrothermal synthesis the substrates were taken out and washed well in deionized water. Post-deposition annealing in air was performed at $350^{\circ} \mathrm{C}$ for $6 \mathrm{~h}$. The annealed samples were named as GZnA and as-prepared unannealed samples were named as GZn.

Panalytical X'Pert PRO high-resolution X-ray diffractometer was used for structural characterization of the samples. Field emission scanning electron microscopy (FESEM) images were recorded on Raith 150 FESEM. Transmission spectra were recorded using Jasco V570 UV-VIS-NIR spectrophotometer. Raman studies and photoluminescence (PL) spectra of the samples were recorded with the help of Horiba Jobin Yvon LabRam HR micro-Raman spectrometer. Briefly, $514.5 \mathrm{~nm} \mathrm{Ar}^{+}$laser was used for Raman studies while 325 $\mathrm{nm} \mathrm{He-Cd}$ laser was used as excitation source for PL studies. The $V-I$ characteristics of the heterojunction has been investigated by Biologic-SP 300 potentiostat/ galvanostat.

\section{Results and discussion}

$\mathrm{ZnO}$ nanorods were grown by the hydrothermal technique, over Mg:GaN substrate using an aqueous solution of zinc acetate and ammonium hydroxide. The FESEM analysis showed vertical growth of hexagonal $\mathrm{ZnO}$ nanorods (figure 1a). The nanorods have a diameter of $200 \mathrm{~nm}$ and a length of $940 \mathrm{~nm}$. The nanorods grew uniformly over the whole substrate. X-ray diffraction studies showed two peaks, corresponding to (0002) and (0004) crystal planes (the $c$ axis growth), of wurtzite crystal structure. Since both $\mathrm{ZnO}$ and $\mathrm{GaN}$ have same crystal structure with very close lattice parameters, the X-ray diffraction peaks of (0002) and (0004) of both $\mathrm{GaN}$ substrate and $\mathrm{ZnO}$ are seen merged together (figure $1 \mathrm{~b}$ ). The rocking curve using high-resolution $\mathrm{X}$-ray diffractometer (inset of figure $1 \mathrm{~b}$ ) clearly resolves the diffraction peaks from $\mathrm{GaN}$ and $\mathrm{ZnO}$.

The micro-Raman spectra of hydrothermally grown nanorod samples (figure 2a) shows $\mathrm{E}_{2}$ (low) and $\mathrm{E}_{2}$ (high) Raman peaks corresponding to both $\mathrm{ZnO}$ and $\mathrm{GaN}$. The Raman peaks matches well with previous reports. ${ }^{15-17}$ The presence of $\mathrm{E}_{2}$ modes only in the $\mathrm{ZnO}$ Raman spectrum is an indicator of crystallinity along the $c$-axis, which suggests that the synthesized nanorods are grown along the $c$-axis. FESEM, XRD and Raman studies confirms the formation of vertically aligned $c$-axis oriented wurtzite crystalline $\mathrm{ZnO}$ nanorods.

PL spectra of $\mathrm{Mg}: \mathrm{GaN}$ under $325 \mathrm{~nm}$ excitation, as shown in figure $2 \mathrm{~b}$ gives a strong peak at $440 \mathrm{~nm}$ and another peak at $365 \mathrm{~nm}$. The $365 \mathrm{~nm}$ emission corresponds to emission from near band edge (NBE) and the $440 \mathrm{~nm}$ emission corresponds to acceptor level created at $2.8 \mathrm{eV}$ due to $\mathrm{Mg}$ doping. ${ }^{18-20} \mathrm{In}$ the case of $\mathrm{ZnO}$ nanorods (figure $2 \mathrm{c}$ and $\mathrm{d}$ ) a sharp emission observed at $380 \mathrm{~nm}$ matches with the band to band transition of $\mathrm{ZnO}$ while another broad deep level emission (DLE)

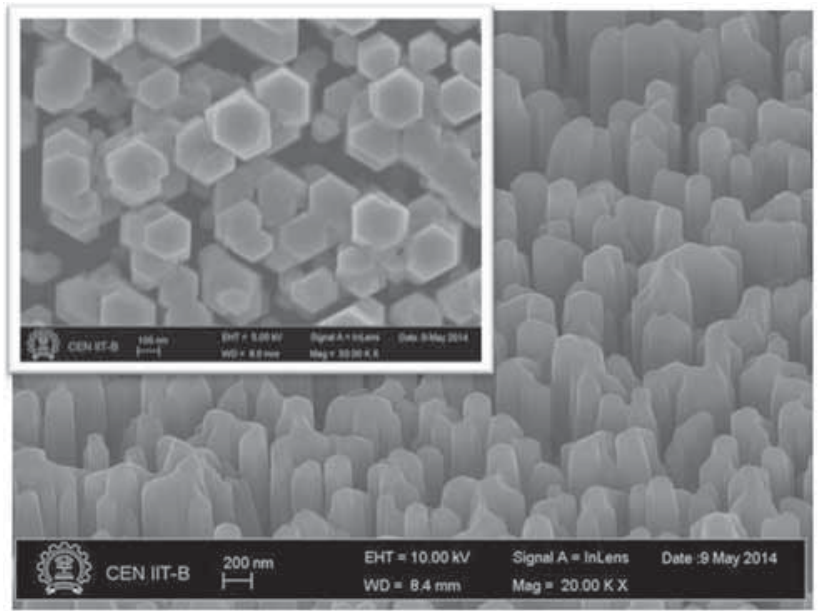

(a)

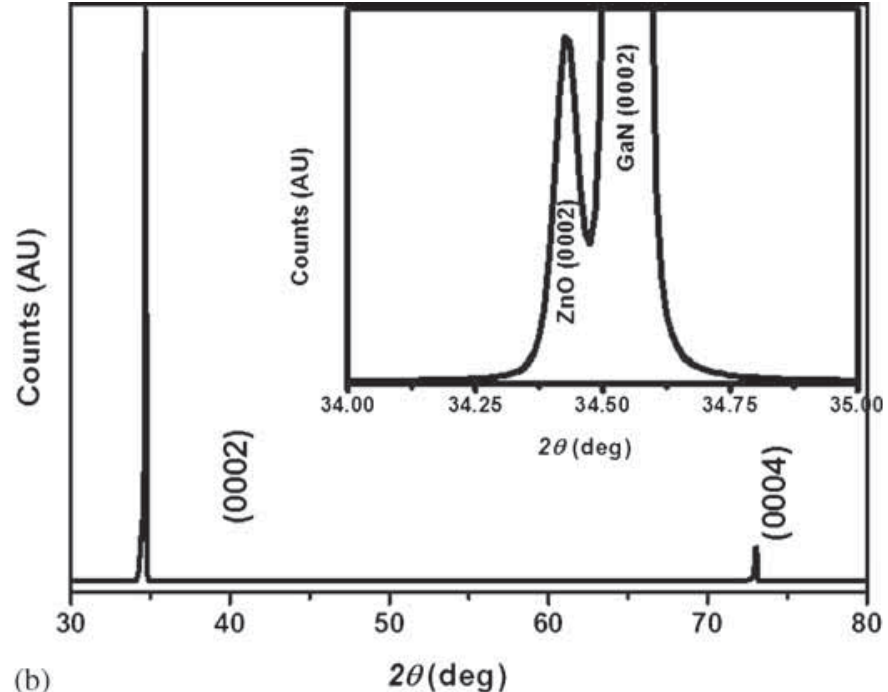

(b)

Figure 1. (a) FESEM image of $\mathrm{ZnO}$ nanorods in $45^{\circ}$ tilted view and top view (inset) and (b) X-ray diffraction pattern of GZnA sample, with rocking curve (inset). 

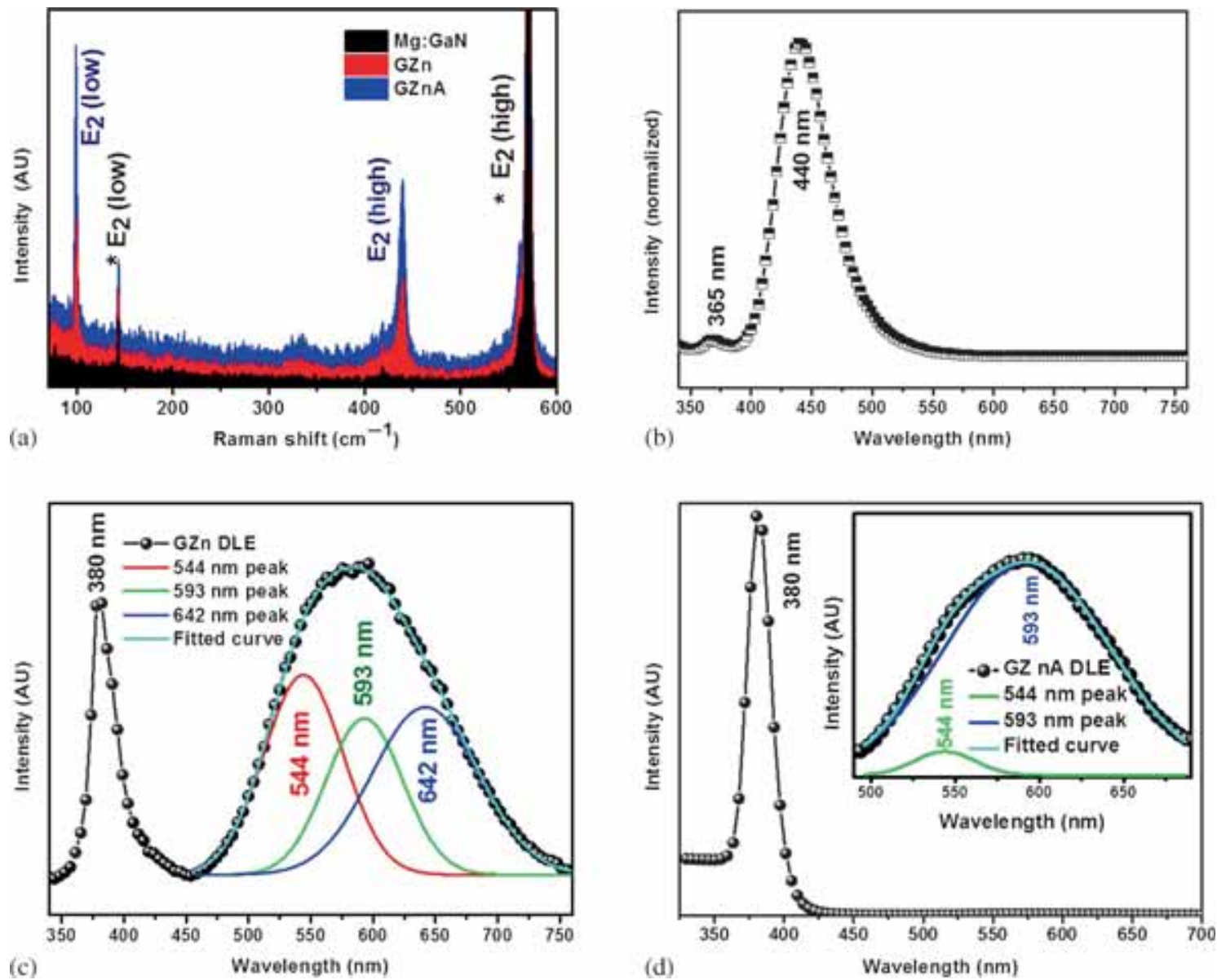

Figure 2. (a) Raman spectra of the samples, (b) photoluminescence (PL) spectrum of $\mathrm{Mg}: \mathrm{GaN}$ thin film, (c) PL spectrum of GZn with its de-convoluted DLE peak and (d) PL of GZnA and its de-convoluted DLE peak (inset of d).

around $580 \mathrm{~nm}$ is observed for unannealed (GZn) sample. The relative emission intensity of DLE with respect to NBE for GZn is $114 \%$, whereas that for the annealed sample (GZnA) is $0.28 \%$, which shows the DLE intensity reduced remarkably on annealing in air and also the strengthening of band to band emission. The broad DLE can be resolved into several emissions (figure $2 \mathrm{c}$ and $\mathrm{d}$ ) and can be assigned to emission from oxygen vacancy $\left(\mathrm{V}_{\mathrm{o}}\right)$, zinc interstitials $\left(\mathrm{Zn}_{\mathrm{i}}\right)$ and oxygen interstitials $\left(\mathrm{O}_{\mathrm{i}}\right)$.

$\mathrm{Au}$ and $\mathrm{Ag}$ metal electrodes were deposited on $\mathrm{ZnO}$ and $\mathrm{Mg}: \mathrm{GaN}$, respectively, to complete the heterojunction device structure as schematically shown in figure $3 \mathrm{a}$. $\mathrm{Ag}$ is found to make ohmic contact (figure $3 \mathrm{a}$ ) with $\mathrm{GaN}$ as reported in literature. ${ }^{21-24} \mathrm{Au}$ is reported to make Schottky contact with $\mathrm{ZnO}$, but the current device structure suggest that as we apply forward bias to $\mathrm{ZnO} / \mathrm{GaN}$ heterojunction, $\mathrm{Au} / \mathrm{ZnO}$ junction will be in reverse bias. Since Schottky junction under reverse bias conducts and functions similar to a contact, the forward characteristics of the heterojunction will be unaffected. The $V-I$ characteristics of the device (figure $3 b$ ) shows the rectifying nature with a rectification ratio of 4.5 at $3.5 \mathrm{~V}$. A series resistance of $\sim 12 \mathrm{k} \Omega$ and a turn on voltage of $2.6 \mathrm{~V}$ were obtained for annealed sample (GZnA). As-prepared devices showed a turn on voltage of $3.87 \mathrm{~V}$ and other parameters are similar as annealed devices. GZnA exhibited a higher current density compared with GZn. Modification of defect energy states may result in slight band realignment, which in turn slightly decreases the energy barrier height at the interface resulting in reduced knee voltage as observed in GZnA. The intensity of X-ray diffraction peaks and Raman peaks were also enhanced on annealing, indicating the decrease in crystalline defects. Improvement in the crystallinity results in better interface between $\mathrm{ZnO}$ nanorods and $\mathrm{Mg}: \mathrm{GaN}$ layers with lesser grain boundaries. Reduction in interfacial defects and grain boundaries results in increased junction current as observed in GZnA. Various parameters of the junction extracted from the $\mathrm{V}-I$ characteristics are tabulated in table 1.

Various energy levels of GZnA obtained from optical studies were used to propose a band diagram as shown in figure 3c. $\Delta E_{\mathrm{c}}$ is the knee voltage, $2.6 \mathrm{~V} . \Delta E_{\mathrm{v}}=E_{\mathrm{g} 2}+$ $\Delta E_{\mathrm{c}}-E_{\mathrm{g} 1}$ was calculated as $2.58 \mathrm{eV}$. PL studies show the presence of an additional acceptor level $\mathrm{Mg}_{1}$ at $2.8 \mathrm{eV}$ below the conduction band of GaN. ${ }^{18,19}$ Three defect levels are identified from PL emission in $\mathrm{ZnO} . \mathrm{Zn}_{\mathrm{i}}$ is at $\sim 0.22 \mathrm{eV}$ below conduction band minimum, $\mathrm{V}_{\mathrm{o}}$ is at $\sim 0.9 \mathrm{eV}$ above 


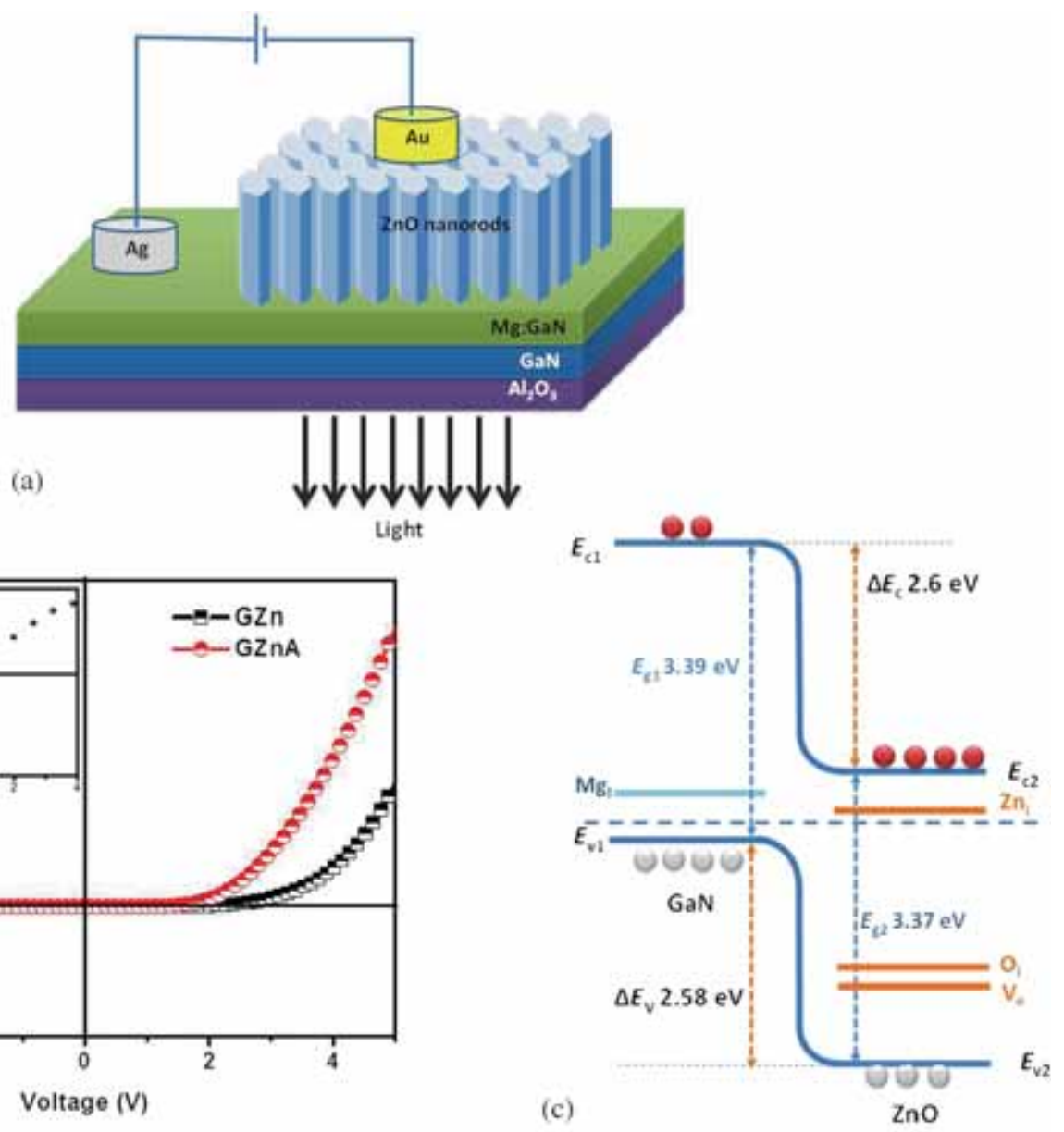

(b)

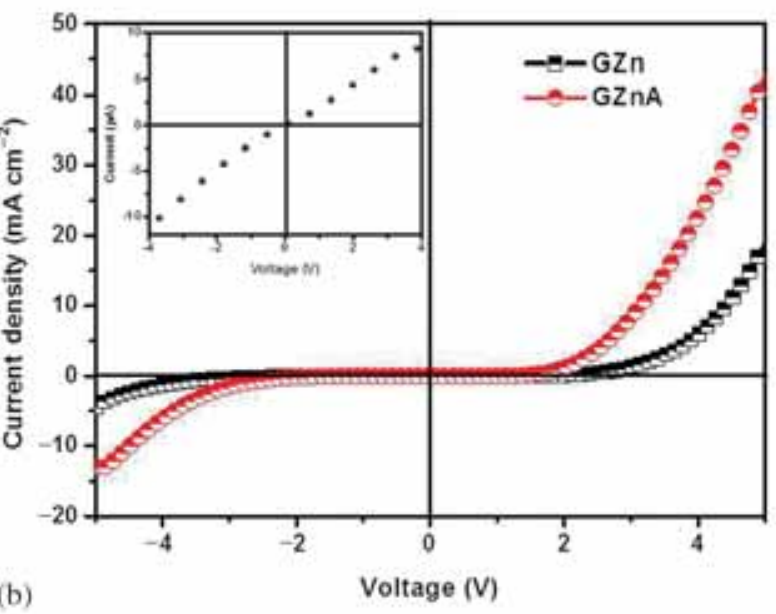

(c)

Figure 3. (a) Schematic representation of the device, (b) $V-I$ characteristics of the heterojunction devices and $V-I$ characteristics of $\mathrm{Ag} / \mathrm{GaN}$ interface (inset of $\mathbf{b}$ ) and (c) band structure of the heterojunction device.

Table 1. Heterojunction parameters extracted from $V-I$ characteristics.

\begin{tabular}{lccc}
\hline Sample & $\begin{array}{c}\text { Knee } \\
\text { voltage }(\mathrm{V})\end{array}$ & $\begin{array}{c}\text { Series } \\
\text { resistance }(\mathrm{k} \Omega)\end{array}$ & $\begin{array}{c}\text { Rectification } \\
\text { ratio at 3.5 V }\end{array}$ \\
\hline GZn & 3.87 & 11.95 & 4.71 \\
GZna & 2.60 & 12.29 & 4.50 \\
\hline
\end{tabular}

valence band maximum and $\mathrm{O}_{\mathrm{i}}$ is at $\sim 2.28 \mathrm{eV}$ below conduction band. ${ }^{25,26}$

The devices show electroluminescence (EL) emission on biasing, as shown in figure 4. All EL emissions of the heterojunction device were measured through the $\mathrm{Al}_{2} \mathrm{O}_{3}$ substrate. As shown in figure $4 \mathrm{a}, \mathrm{GZn}$ and GZnA show completely different EL emission characteristics. GZn sample exhibits one peak centred around $420 \mathrm{~nm}$ another broad peak centred around $580 \mathrm{~nm}$ and a shoulder peak around $385 \mathrm{~nm}$. The $420 \mathrm{~nm}$ emission observed for GZn can be attributed to the electronic transition from $\mathrm{Zn}_{\mathrm{i}}$ to valence band maximum, the band diagram (figure $3 b$ ) also supports this fact. The broad emission at $580 \mathrm{~nm}$ can be attributed to the contributions from various defect states in the $\mathrm{ZnO}$ semiconductor. For heterojunction grown over annealed sample the dominant peak is at $385 \mathrm{~nm}$. The $420 \mathrm{~nm}$ emission almost quenched in GZnA. The $385 \mathrm{~nm}$ emission can be attributed to emission originating from band to band transition in $\mathrm{ZnO}$. From the PL and EL studies, it can be concluded that on annealing various defect states in the semiconductor material get modified remarkably including $\mathrm{Zn}_{\mathrm{i}}$. Hence further emissions originating from these defect states gets quenched, while the band to band transition starts to dominate the spectrum. EL emission is observed after a threshold voltage of $3 \mathrm{~V}$ forward bias for both the devices, which lower compared with previous reports on similar devices. ${ }^{10,14}$

The EL peak under forward bias is found to be blue shifting on increasing junction current. The EL emission, originate from the free electron-acceptor transition (conduction band to acceptor transition) and from the donor-to-acceptor (DAP) transition. As injection current increases, radiative electron-hole recombination increases. Thus the blue shift and increase in intensity of intense EL emission peak for higher injection currents can be attributed to the radiative electron-hole-recombination due to electron injection from $\mathrm{ZnO}$ nanorods to $\mathrm{Mg}$ : $\mathrm{GaN}$ thin film. ${ }^{27,28}$ 

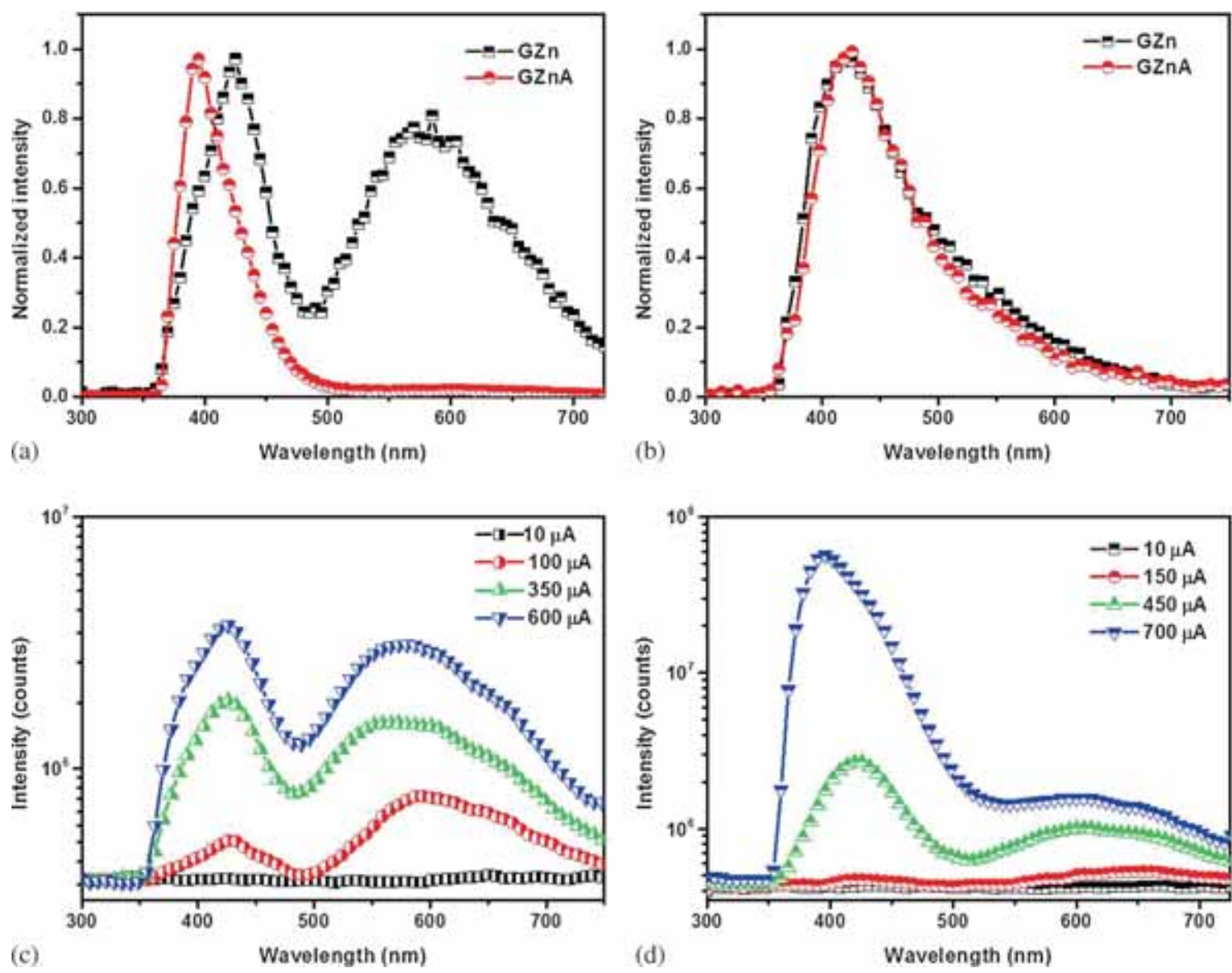

Figure 4. Normalized EL spectra observed in GZn and GZnA under (a) forward bias of $10 \mathrm{~V}$ and (b) reverse bias of $-10 \mathrm{~V}$. The dependence of output light on junction current of (c) GZn and (d) GZnA.

The heterojunction device emitted light under reverse bias also. The EL emission is observed after a threshold voltage of $5 \mathrm{~V}$ under reverse bias. The EL peak at $430 \mathrm{~nm}$ extends almost up to $700 \mathrm{~nm}$. The emission wavelength under reverse bias condition matches close to the emission from $\mathrm{Mg}$ acceptor level. Wu et $a l^{14}$ observed similar EL emissions under reverse bias from $\mathrm{n}-\mathrm{ZnO} / \mathrm{p}-\mathrm{GaN}$ heterojunction. ${ }^{14}$ According to them, the actual recombination of charge carriers occurs in GaN thin film. Hence the observed reverse emission can be attributed to the emissions from deep and shallow $\mathrm{Mg}$-acceptor levels.

There is a non-linear dependence of EL intensity on junction current, as shown in figure 5. The non-linear dependence are observed for both forward and reverse bias conditions on both the samples. The EL intensity of GZnA increases drastically, compared with GZn, under forward and reverse bias conditions. Increase in intensity of EL emission can be viewed as increase in the number of radiative recombination. It is already seen that both GZn and GZnA has inherent defect states, which is predominant in GZn. At any time the injected carriers needs to go through these defect states, which can eventually be trapped inside. As injection current increases various defect states start to fill up fast allowing rest of the charge carriers to recombine radiatively. In lower junction currents the rate of trapping or rate of non-radiative recombination will be comparable to the rate of injected carriers, resulting in lower possibility of radiative recombination. Since the number of defect states is constant, on increasing the injection current (rate), though further increase in trapping occurs, the probability of radiative recombination will be higher. This may be a reason for obtaining nonlinear increase in EL intensity with injection current. It is also understandable that the rate of increase of intensity in GZn is lower than that of GZnA as the number of defect states is higher for GZn.

The CIE co-ordinates corresponding to the emissions from LEDs under various biasing conditions, are shown in figure 6. Under a forward bias GZn emitted white light with CIE co-ordinates of $(0.35,0.33)$. Under reverse bias strong blue emission is seen from both the devices. Intense emission peak for annealed device $(\mathrm{GZnA})$ is in the blue region. Even for GZnA under $10 \mathrm{~V}$ forward biasing, the emission is observed outside the standard triangle indicating UV content in the emission, which is also evident in figure $4 \mathrm{~d}$. It can also be noted that for lower junction current EL emission from defect states dominates and as junction current increases band to band emission dominates (figure $4 \mathrm{c}$ and $\mathrm{d}$ ) with several orders of magnitude higher than the defect emissions. Though PL studies revealed the presence of NBE and DLE, the dependence of emission intensities of band to band 

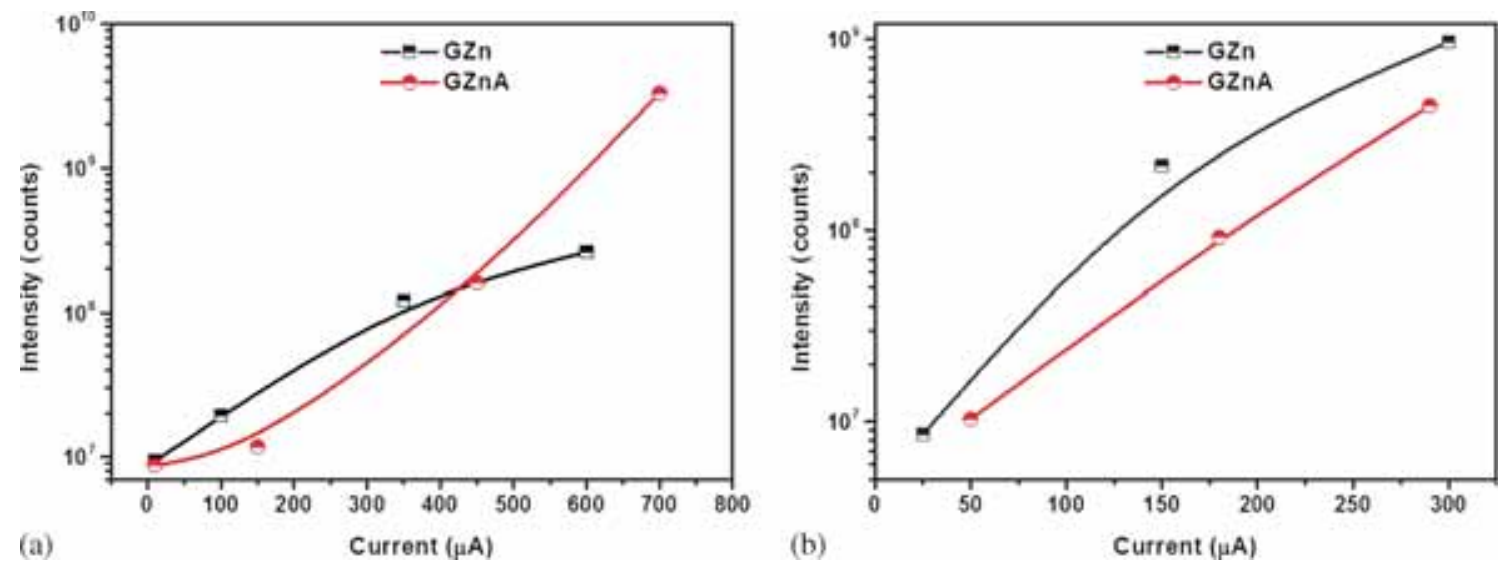

Figure 5. Dependence of EL output intensity on junction current for the heterojunctions under (a) forward bias and (b) reverse bias.
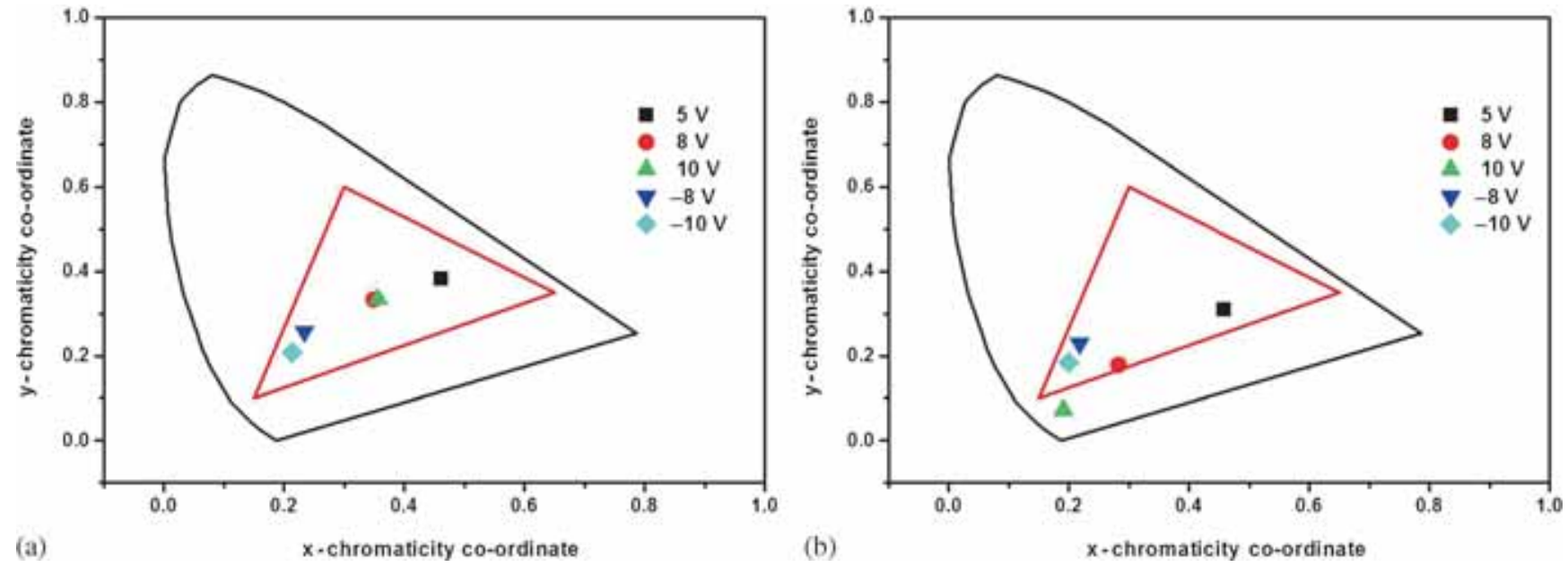

Figure 6. CIE co-ordinates of (a) GZn and (b) GZnA LEDs under different biasing conditions.

emission and defect emission on junction current may be the reason for the observed shifts in CIE co-ordinates under various forward biasing conditions. The CIE co-ordinates explained the quality of emission from fabricated LEDs. The study shows that the LED emission can be tuned by careful tuning of defect states in the semiconductors, and suitable biasing.

\section{Conclusions}

$\mathrm{n}-\mathrm{ZnO} / \mathrm{p}-\mathrm{GaN}$ heterojunction was successfully fabricated by vertically growing $\mathrm{ZnO}$ nanorods over $\mathrm{Mg}: \mathrm{GaN}$ by relatively simple hydrothermal process. As synthesized nanorods have wurtzite crystal structure. PL studies showed various defect related emissions from both $\mathrm{Mg}: \mathrm{GaN}$ and $\mathrm{ZnO}$ regions. $\mathrm{ZnO}$ defect emissions quenched considerably on annealing in air. The heterojunction showed rectifying nature with a rectification ratio of 4.5 at $3.5 \mathrm{~V}$. The device emits light under forward and reverse bias. The EL emission wavelength changes on annealing the device, indicating output wavelength can be tuned by suitably altering the defect states in the semiconductor. GZnA showed blue emission while GZn sample emitted a strong blue light and a broad yellow light. The device showed a non-linear dependence of output light with junction current. Calculated CIE co-ordinates of the LED emissions showed signature of white and blue emissions under various conditions. LED emission found to be tuned with the help of various bias conditions, and also with the help of modification in the defect states.

\section{Acknowledgements}

We also acknowledge DST Nanomission for the financial support. L S Vikas acknowledges UGC for fellowship under UGC-RFSMS scheme.

\section{References}

1. Nakamura S, Yasuhiro H and Masayuki S 1991 Appl. Phys. Lett. $\mathbf{5 8} 2021$ 
2. Akasaki I 1997 MRS Proc. 4823

3. Verma J, Prem K K, Vladimir P, Amit V, Huili G X and Debdeep J 2013 Appl. Phys. Lett. 102041103

4. Mao Z, Ying-Chun Z, Yang W and Lin G 2014 J. Mater. Sci. 494439

5. Viana B, Pauporte T, Lupan O, Devis L and Gacoin T 2014 Proc. SPIE $898789871 \mathrm{~T}$

6. Wang J, Xiping J, Chunhua Y and Jianhua L 2005 J. Electrochem. Soc. 152 G186

7. Kim D C, Won S H, Bo H K, Hyung K C and Chang H H 2007 Physica B: Condens. Matter 401386

8. Schuster F, Bernhard L, Reza R Z, Cesar M, Joan R M, Jordi A and Martin S 2014 ACS Nano 84376

9. Abbasi M A, Zafar H I, Mushtaque H, Omer N and Magnus W 2013 Nanoscale Res. Lett. 8320

10. Ng A M C, Xi Y Y, Hsu Y F, Djurisić A B, Chan W K, Gwo S, Tam H L, Cheah K W, Fong P W K, Lui H F and Surya C 2009 Nanotechnology 20445201

11. Jha S, Wang C D, Luan C Y, Liu C P, Bin H, Kutsay O, Bello I, Zapien J A, Zhang W J and Lee S T 2012 J. Electron. Mater. 41853

12. Yin Z, Xiaoyan L, Hanchao Y, Yongzhong W, Xiaopeng H, Min H and Xiangang X 2013 IEEE Photonic Technol. Lett. 25 1989

13. Yin Z, Xiaoyan L, Yongzhong W, Xiaopeng H and Xiangang X 2012 Opt. Express 201013

14. Wu J H, Shu Y L, Shuti L, Yu L J, Guo P R and Xin P Q 2012 Appl. Phys. A 109489

15. Zhu H, Javed I, Hongjun X and Dapeng Y 2008 J. Chem. Phys. 129124713
16. Gomi M, Naoko O, Kenichi O and Mikio K 2003 Jpn. J. Appl. Phys. 42481

17. Davydov V, Yu K, Goncharuk I, Smirnov A, Graul J, Semchinova O, Uffmann D, Smirnov M, Mirgorodsky A and Evarestov R 1998 Phys. Rev. B 5812899

18. Kaufmann U, Kunzer M, Maier M, Obloh H, Ramakrishnan A, Santic B and Schlotter P 1998 Appl. Phys. Lett. 721326

19. Monemar B, Paskov P P, Pozina G, Hemmingsson C, Bergman J P, Khromov S, Izyumskaya V N, Avrutin V, Li X, Morkoc H, Amano H, Iwaya M and Akasaki I 2014 J. Appl. Phys. 115 053507

20. Monemar B, Sergey K, Galia P, Plamen P, Peder B, Carl H, Lars H, Hiroshi A, VItaliy A, Xing L and Madis M 2013 Jpn. J. Appl. Phys. 52 08JJ03

21. Song J O and Tae Y S 2004 Appl. Phys. Lett. 856374

22. Song J O, Hyun G H, Joon W J, Jung I S, Ja S J and Tae Y S 2008 Electrochem. Solid-State Lett. 11 H36

23. Song J O, Jun S H and Tae Y S 2010 IEEE Trans. Electron. Devices 5742

24. Song J O, Dong S L, Park Y, Chae S W and Tae Y S 2005 IEEE Photonics Technol. Lett. 17291

25. Rodnyi P A and Khodyuk I V 2011 Opt. Spectrosc. 111 776

26. Ahn C H, Young Y K, Dong C K, Sanjay K M and Hyung K C 2009 J. Appl. Phys. 105013502

27. Myoung J M, Shim K H, Kim C, Gluschenkov O, Kim K, Kim S, Turnbull D A and Bishop S G 1996 Appl. Phys. Lett. 69 2722

28. Jeong M C, Byeong Y O, Moon H H, Sang W L and Jae M M 2007 Small 3568 